\title{
Cross-linked cyclodextrin-based material for treatment of metals and organic substances present in industrial discharge waters
}

\author{
Élise Euvrard ${ }^{1}$, Nadia Morin-Crini ${ }^{1}$, Coline Druart ${ }^{1}$, Justine Bugnet ${ }^{1}$, Bernard Martel ${ }^{2}$, \\ Cesare Cosentino ${ }^{3}$, Virginie Moutarlier ${ }^{4}$ and Grégorio Crini ${ }^{* 1}$
}

\author{
Full Research Paper \\ Address: \\ ${ }^{1}$ Chrono-environnement, UMR 6249 usc INRA, University of \\ Bourgogne Franche-Comté, 16 route de Gray, 25000 Besançon, \\ France, ${ }^{2}$ UMET UMR 8207, Ingénierie des Systèmes Polymères, \\ University of Lille 1, 59655 Villeneuve d'Ascq, France, ${ }^{3} \mathrm{G}$. Ronzoni \\ Institute for Chemical and Biochemical Research, 81 via G. Colombo, \\ 20133 Milano, Italy and ${ }^{4}$ Chrono-environnement, Institut UTINAM, \\ UMR 6213, University of Bourgogne Franche-Comté, 16 route de \\ Gray, 25000 Besançon, France \\ Email: \\ Grégorio Crini* - gregorio.crini@univ-fcomte.fr \\ * Corresponding author \\ Keywords: \\ alkylphenols; adsorption; cyclodextrin; metals; polycyclic aromatic \\ hydrocarbons \\ Beilstein J. Org. Chem. 2016, 12, 1826-1838. \\ doi:10.3762/bjoc. 12.172 \\ Received: 09 May 2016 \\ Accepted: 29 July 2016 \\ Published: 12 August 2016 \\ This article is part of the Thematic Series "Superstructures with \\ cyclodextrins: Chemistry and applications IV". \\ Guest Editor: G. Wenz \\ (C) 2016 Euvrard et al.; licensee Beilstein-Institut. \\ License and terms: see end of document.
}

\begin{abstract}
In this study, a polymer, prepared by crosslinking cyclodextrin (CD) by means of a polycarboxylic acid, was used for the removal of pollutants from spiked solutions and discharge waters from the surface treatment industry. In spiked solutions containing five metals, sixteen polycyclic aromatic hydrocarbons (PAH) and three alkylphenols (AP), the material exhibited high adsorption capacities: $>99 \%$ of $\mathrm{Co}^{2+}, \mathrm{Ni}^{2+}$ and $\mathrm{Zn}^{2+}$ were removed, between 65 and $82 \%$ of the PAHs, as well as 69 to $90 \%$ of the APs. Due to the structure of the polymer and its specific characteristics, such as the presence of carboxylic groups and CD cavities, the adsorption mechanism involves four main interactions: ion exchange, electrostatic interactions and precipitation for metal removal, and inclusion complexes for organics removal. In industrial discharge waters, competition effects appeared, especially because of the presence of calcium at high concentrations, which competed with other pollutants for the adsorption sites of the adsorbent.
\end{abstract}

\section{Introduction}

Although considerable efforts have been made by the industrial sector over the last 30 years, the problem of water pollution still remains a significant concern. Particularly affected by this issue are the discharge waters (DWs) of the surface treatment (ST) industries known for using large amounts of water and chemicals in their manufacturing processes. Despite these industries 
have their own treatment plants, generally physicochemical decontamination steps, the DWs still contain non-negligible amounts of pollutants. Among them, metals (in particular chromium, nickel and zinc) are commonly found at concentrations in the range of milligrams per liter, and organic molecules, such as polycyclic aromatic hydrocarbons (PAHs) and alkylphenols (APs) at concentrations varying from hundreds of nanograms per liter to some micrograms per liter [1].

However, it is extremely difficult to remove pollutants present at low concentrations (a few hundreds of micrograms per liter for some organic substances in DWs). For this purpose, specific systems can be added, called effluent finishing treatments. A sequential dual approach can be considered: firstly, adsorption onto carbon to remove organics (e.g., solvents, oils, PAHs and volatile organic compounds) combined with ion-exchange and/ or chelation by means of organic resins to remove inorganic pollutants (e.g., metals and anions such as fluorides). Charles et al. [2] recently reported that this type of sequence is acknowledged for its efficiency. However, it is an approach to water treatment that combines two methods of separation using two distinct commercial materials. To our knowledge, materials able to combine the two functions are rare. Recently, bifunctional natural derivatives have been proposed for this purpose. For example, Zhao et al. [3] proposed a new cyclodextrin-based material for the simultaneous adsorption of metals and cationic dyes. Zhang et al. [4] studied the removal of cobalt and 1-naphthol onto magnetic nanoparticles containing cyclodextrin and iron and Yang et al. [5] proposed a new nanocomposite adsorbent for the simultaneous removal of organic and inorganic substances from water.

Here, we propose to use a single cross-linked cyclodextrinbased polymer for the removal of metals and organic pollutants present in polycontaminated effluents. Cyclodextrins (CDs), synthetic substances obtained from the enzymatic degradation of starch, belong to the family of cage molecules. They present remarkable encapsulation properties leading to a host-guest relationship with organic substances [6-9]. These cyclic oligosaccharides are water soluble in their native form and are often modified to prepare novel insoluble CD-based materials. Two patents published by Martel et al. [10], and Trotta et al. [11] can be consulted for the use of carboxylic acids and pyromellitic dianhydride, respectively, as agents to cross-linking CDs. Other cross-linking agents such as epichlorohydrin, ethylene glycol diglycidyl ether, glutaraldehyde, benzoquinone or isocyanates can be also used [1,12].

The main objective of the study was to investigate the adsorption capacities of a non-conventional and versatile CD-based material crosslinked with 1,2,3,4-butanetetracarboxylic acid
(BTCA) toward several inorganic and organic elements. Performances of such systems were evaluated in the presence of spiked solutions and real DWs from ST industry containing five metals, 16 PAHs, three APs (model pollutants present in DWs from treatment-surface industries) in the presence and in the absence of calcium. The polymer showed high adsorption capacities in spiked solutions but adsorption strongly decreased in discharge waters due to some competition effects, notably between inorganics for adsorption sites.

\section{Results \\ Material characterization}

The cross-linked polymer used in this study is presented in Figure 1. In the control test (solution without pollutant), polymer addition led to large $\mathrm{pH}$ variations. The non-activated polyBTCA-CD (COOH form) decreased the $\mathrm{pH}$ value from 6 to 4.3 after 20 min of shaking whereas activated polyBTCA-CD $\left(\mathrm{COO}^{-} \mathrm{Na}^{+}\right.$form) led to a $\mathrm{pH}$ increase from 6 to 7.2 after $5 \mathrm{~min}$ shaking. In both cases the final $\mathrm{pH}$ remained constant over several hours.

The ion-exchange capacity (IEC) was equal to $0.705 \mathrm{mmol}$ of $\mathrm{COOH}$ functions per gram of polymer. The point of zero charge (PZC) was plotted and followed the linear equations $\mathrm{y}=-0.9639 x+6.1422$ and $\mathrm{y}=-0.9233 x+3.138$ indicating a $\mathrm{pH}$ of 6.4 and 3.4 for the PZC of activated and non-activated polyBTCA-CD, respectively (Figure 2 ).

Figure 3 shows the XRD pattern of non-activated and activated polymers. These diffractograms indicate a wide amorphous peak between values of $2 \theta$ of 10 and $30^{\circ}$, highlighting that polymers are amorphous. No significant differences were observed between the two types of polymer.

Solid-state ${ }^{13} \mathrm{C}$ NMR spectra of the polymer are presented in Figure 4. The cross polarization magic angle spinning (CPMAS) spectrum shows the peaks of disordered cyclodextrin (broad signals) in the range of 50-110 ppm. Three strong broad bands attributable to the glucopyranose unit can be observed. The peak at $101 \mathrm{ppm}$ is attributed to the anomeric carbon C-1: this confirms the presence of glucose units in the polymer. In the range of 50-110 ppm, the $\mathrm{CH}_{2}$ signals of $\mathrm{CD}$ (C-6, C-6' and C-7) are completely hidden by the C-2, C-3 and C-5 peaks of the glucopyranose units. In the MAS spectrum, three $\mathrm{CH}_{2}$ signals are clear and the signals at 65, 62.1 and 60.2 ppm are attributable to $\mathrm{CH}_{2}$ in positions C-6', C-6 and C-7, respectively. These attributions were confirmed using cross-polarization with a polarization inversion sequence (CPPI spectrum not shown), which revealed three $\mathrm{CH}_{2}$ signals due to the $\mathrm{CD}$ and also a peak at $30.15 \mathrm{ppm}$ corresponding to $\mathrm{CH}_{2}$ groups introduced by the cross-linking agent. As expected, the signals of the BTCA 


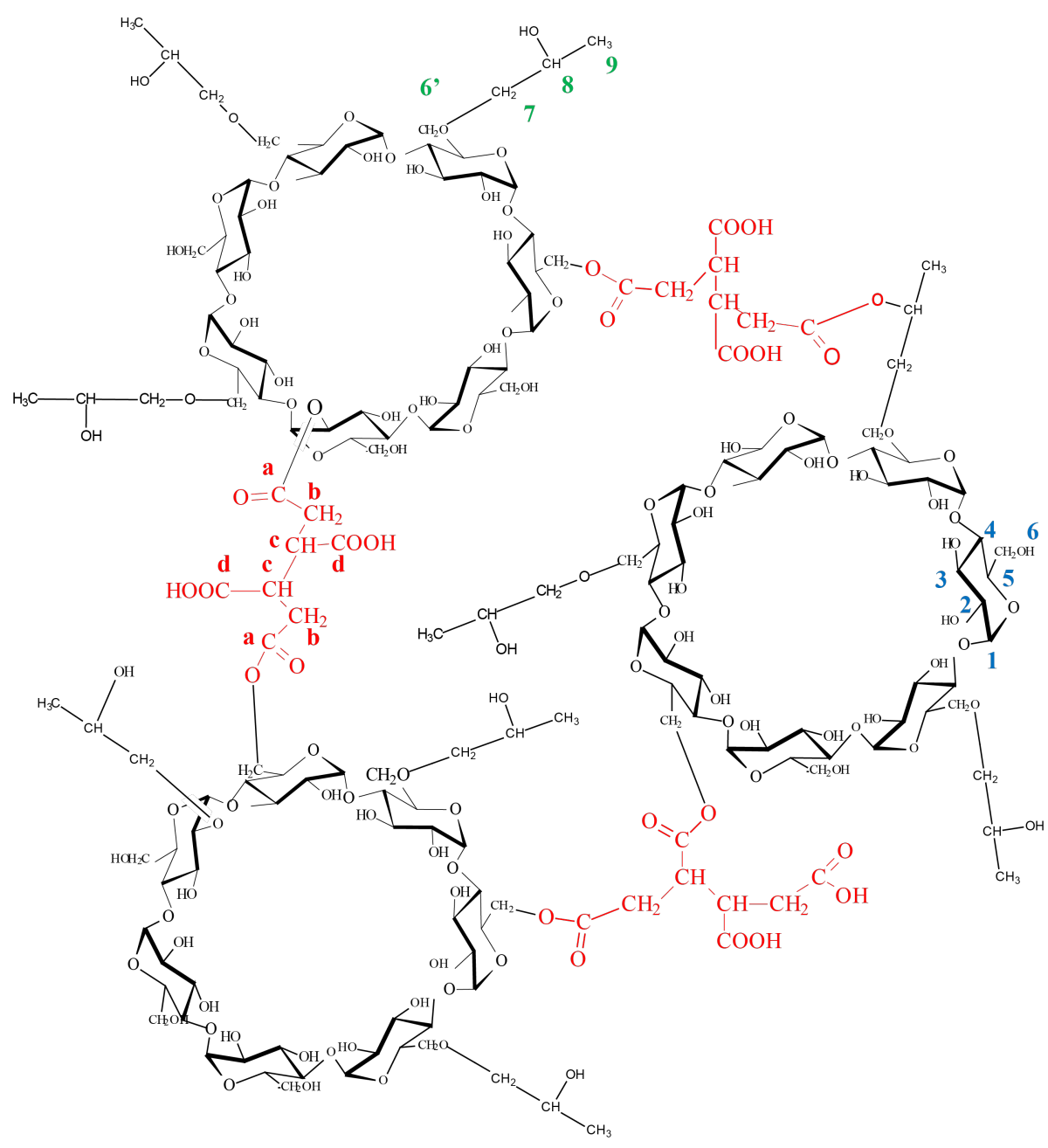

Figure 1: Chemical structure of the non-activated polyBTCA-CD.

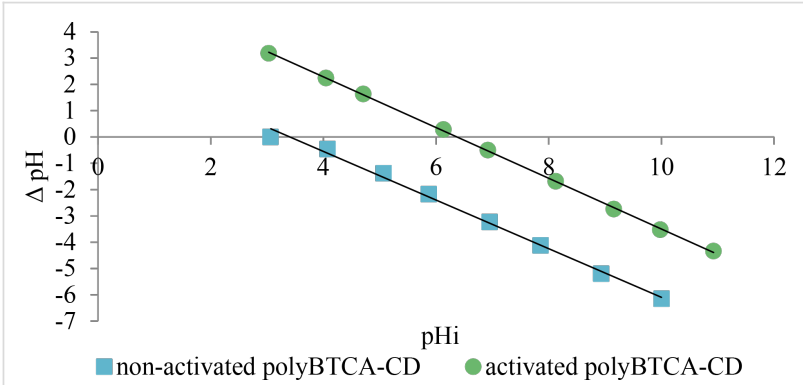

Figure 2: Determination of the $\mathrm{PZC}$ for the non-activated and activated polyBTCA-CD polymers ( $\mathrm{pHi}$ : initial $\mathrm{pH}$ value, see also Experimental section).

crosslinking agent can be clearly distinguished (labeled a, b, c and d). In particular, the carbon of the carboxylic groups appears at $172.2 \mathrm{ppm}$. This peak $(\mathrm{a}, \mathrm{d})$ corresponds to esterified and free carboxylic groups of BTCA present in free carboxylic acids and in ester crosslinks, respectively. In the CPMAS spec-

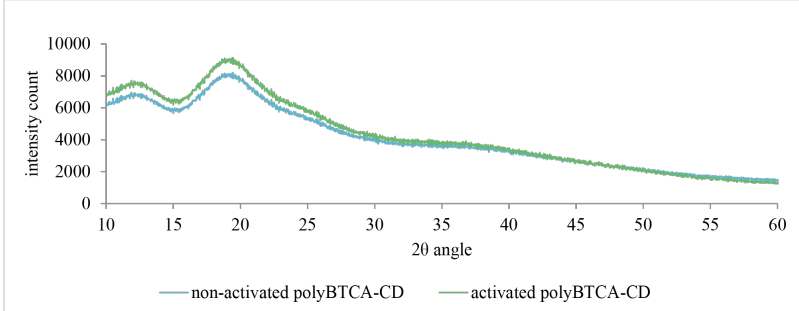

Figure 3: XRD pattern of the two polymers: non-activated and activated polyBTCA-CD.

trum we also note the presence of additional peaks due to the hydroxypropyl group present in the $\mathrm{CD}$, and in particular the $\mathrm{CH}_{3}$ group (C-9 carbon) at $15.3 \mathrm{ppm}$. The comparison between the CPMAS and MAS spectra shows a different intensity for this methyl signal reflecting the greater mobility of this group, as expected. Paradoxically, the intensity of the carbonyl signal does not increase in the MAS spectrum compared with the 


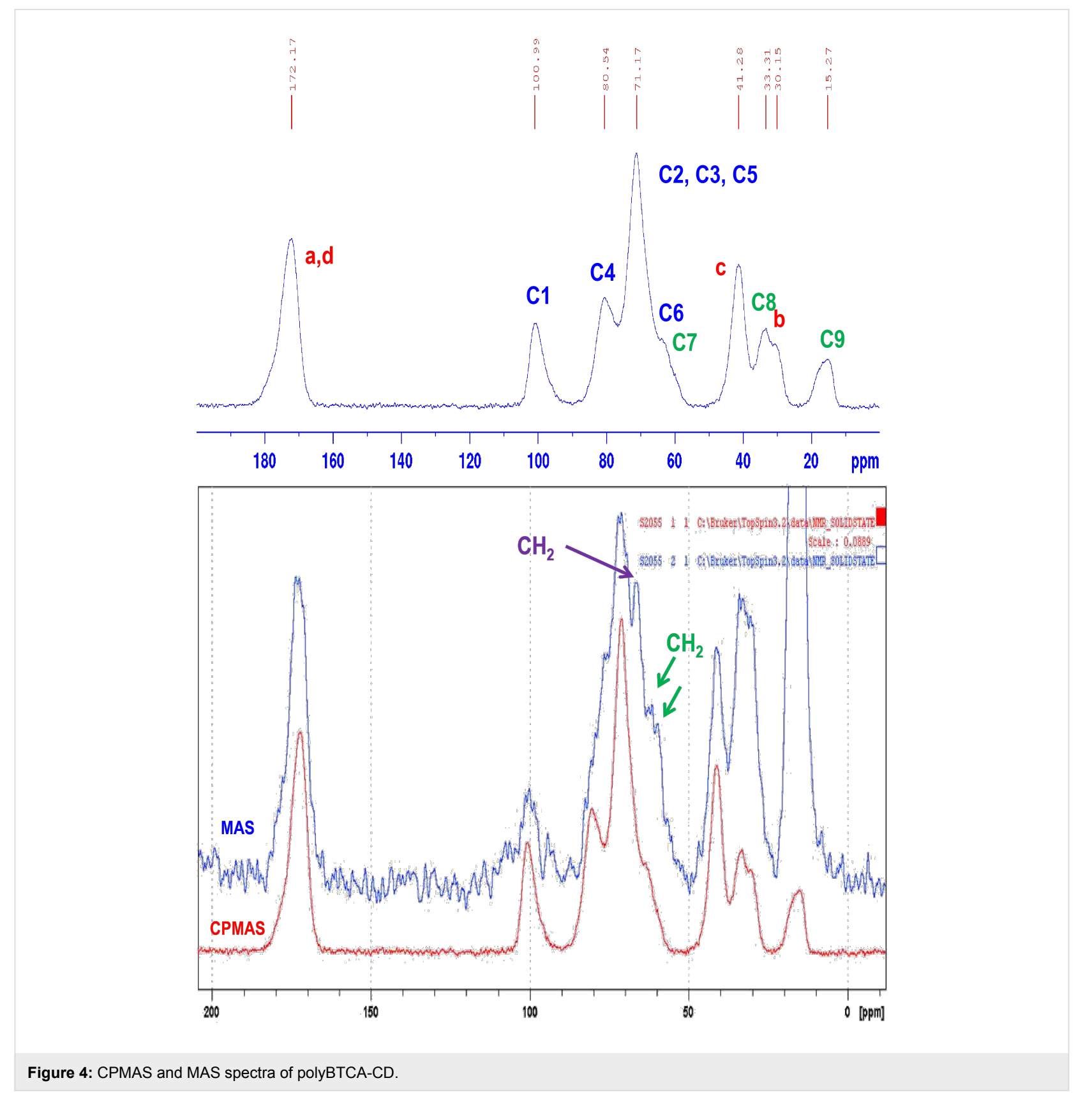

signal of the methyl group of CD. Finally, no significant differences were obtained between the non-activated polyBTCA-CD and the activated polyBTCA-CD spectra.

\section{Metal adsorption}

\section{Effect of activation ( $\mathrm{NaHCO}_{3}$ treatment)}

The activated polymer is more efficient than the non-activated polymer regardless of the dose (Figure 5). The activation enhanced the removal by $69 \%, 92 \%, 78 \%, 92 \%$ and $92 \%$ at a polymer concentration of $2 \mathrm{~g} \cdot \mathrm{L}^{-1}$ for $\mathrm{Al}^{3+}, \mathrm{Co}^{2+}, \mathrm{Cr}^{3+}, \mathrm{Ni}^{2+}$ and $\mathrm{Zn}^{2+}$, respectively. Moreover, it appears that a polymer concentration of $2 \mathrm{~g} \cdot \mathrm{L}^{-1}$ is enough to treat an inorganic load of
$50 \mathrm{mg} \cdot \mathrm{L}^{-1}$. Thus, for all the following experiments, the polymers were activated and a concentration of $2 \mathrm{~g} \cdot \mathrm{L}^{-1}$ was used.

\section{Adsorption kinetics}

Figure 6 shows the adsorption kinetics for two solutions containing five metals at $1 \mathrm{mg} \cdot \mathrm{L}^{-1}$ and $10 \mathrm{mg} \cdot \mathrm{L}^{-1}$. For these two concentrations, $100 \%$ removal was reached for most species except for A11 and Cr1 systems, which reached a state of dynamic equilibrium. However, the adsorption time changed with the concentration and with the metals. At $1 \mathrm{mg} \cdot \mathrm{L}^{-1}$ the adsorption kinetics was fast: in 5 min equilibrium was reached for the metals except for $\mathrm{Al}^{3+}(240 \mathrm{~min})$. At $10 \mathrm{mg} \cdot \mathrm{L}^{-1}$ for 


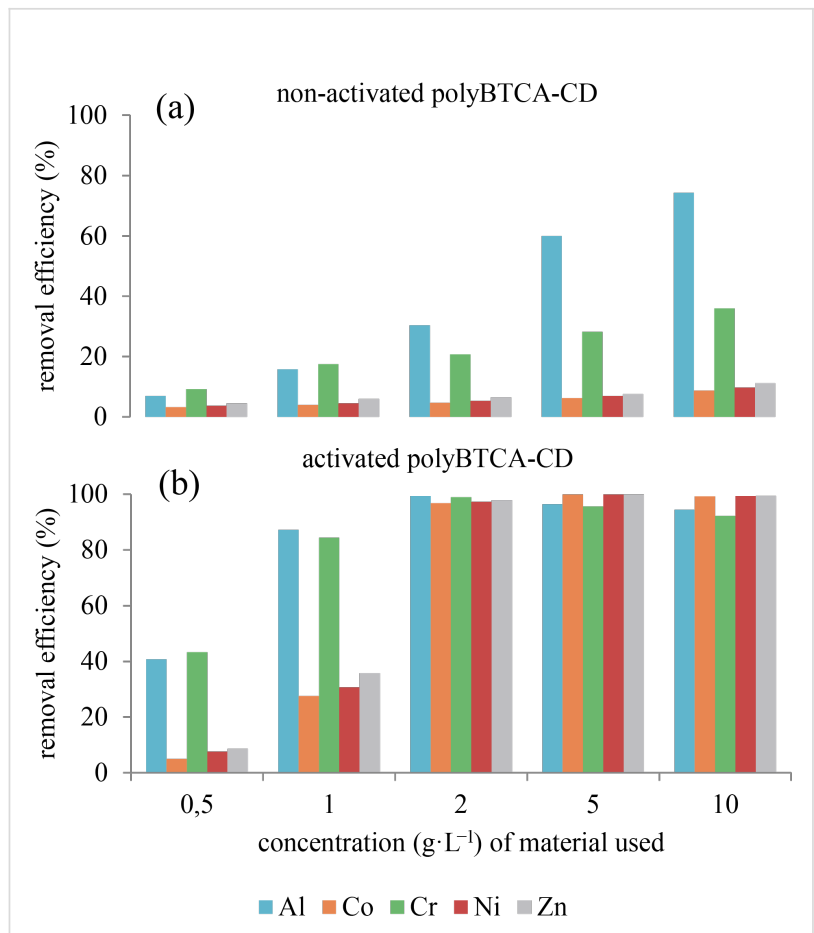

Figure 5: Adsorption capacity (\%) of (a) the non-activated and (b) the activated $\left(\mathrm{NaHCO}_{3}\right.$ treatment) polyBTCA-CD at different concentrations for five metals (at $10 \mathrm{mg} \cdot \mathrm{L}^{-1}$ metal).

$\mathrm{Co}^{2+}, \mathrm{Ni}^{2+}$ and $\mathrm{Zn}^{2+}$, equilibrium time increased to $30 \mathrm{~min}$, while for $\mathrm{Al}^{3+}$ and $\mathrm{Cr}^{3+}$ it decreased to $30 \mathrm{~min}$. These results were obtained in triplicate with small standard deviations, indicating the reproducibility of the experiments. For the two exper- iments we noted an increase of $\mathrm{pH}$ values ranging from 3.9 and 4.4 for the initial $\mathrm{pH}$ (pHi) to 6.2 and 7.3 for the final $\mathrm{pH}(\mathrm{pHf})$ for concentrations of $10 \mathrm{mg} \cdot \mathrm{L}^{-1}$ and $1 \mathrm{mg} \cdot \mathrm{L}^{-1}$, respectively.

\section{Influence of metal and calcium concentration}

The results show that activated polyBTCA-CD is able to treat metal solutions from low concentrations (a few micrograms in SS3 and SS4 in Table 1) to high concentrations (ten milligrams for each metal (SS1 in Table 1). The exact composition of each spiked solution (SS) is given in the Experimental section. In addition, it was observed that without $\mathrm{Ca}^{2+}$ cations the removal efficiency was above $99 \%$, except for aluminum and chromium (Table 1). When expressing these results in mmol of total metal retained per gram of polymer, it can be noted that for the highest concentration of metals $\left(10 \mathrm{mg} \cdot \mathrm{L}^{-1}\right)$, the polymer retained $0.466 \mathrm{mmol} \cdot \mathrm{g}^{-1}$. When calcium ions were added (SS5 in Table 1), $\mathrm{Cr}^{3+}$ was better retained than in the solution without calcium ( $85 \%$ compared to $38 \%$ ) while the retention of $\mathrm{Al}^{3+}$ remained constant. For the three other metals, the retention dramatically decreased $(<41 \%)$ in the presence of calcium.

\section{$\mathrm{PAH}$ and $\mathrm{AP}$ adsorption}

Figure 7a shows that the polyBTCA-CD can take up PAHs since the polymer removed between $74 \%$ and $79 \%$ of the global PAH load. It was also observed that removal was more efficient for heavy PAHs (89\% adsorption) than for the lighter ones (62\% adsorption). Following $\mathrm{PAH}$ adsorption the $\mathrm{pH}$ ranged from 6 to 7.6 at the end of the experiment. The polymer successfully removed APs as shown in Figure $7 \mathrm{~b}$. It can be noted that an increase of AP concentration led to a decrease in adsorp-

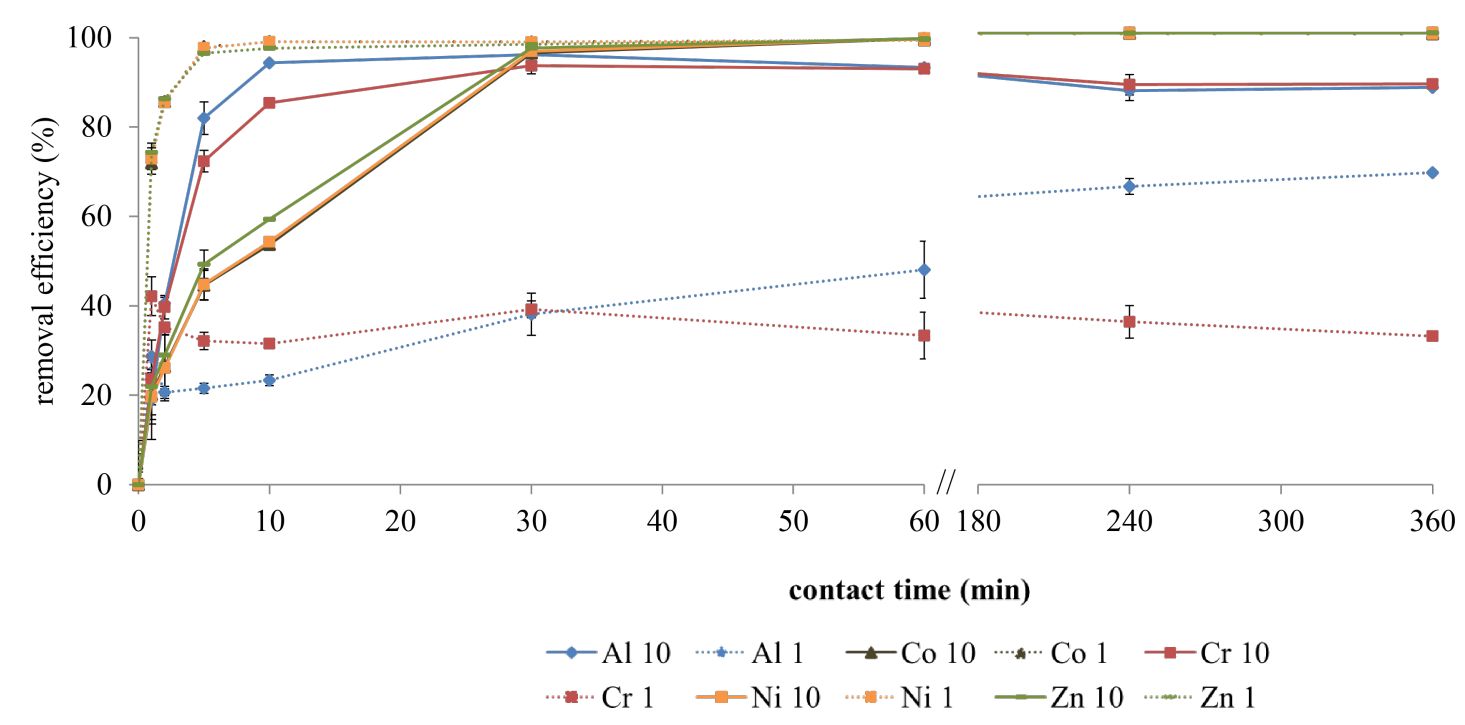

Figure 6: Adsorption kinetics for two solutions containing five metals at two concentrations (solution at $10 \mathrm{mg} \cdot \mathrm{L}^{-1}$ : full lines; solution at $1 \mathrm{mg} \cdot \mathrm{L}^{-1}$ : dashed lines) expressed as removal efficiency in $\%(n=3)$. 
Table 1: Efficiency of activated polyBTCA-CD expressed in \% (concentration $\left.=2 \mathrm{~g} \cdot \mathrm{L}^{-1}\right)$ to treat several metal spiked solutions SS $(n=3)$. See Experimental section for the exact compositions of the spiked solutions SS.

$\begin{array}{lllllll} & \mathrm{Al}^{3+} & \mathrm{Co}^{2+} & \mathrm{Cr}^{3+} & \mathrm{Ni}^{2+} & \mathrm{Zn}^{2+} & \mathrm{Ca}^{2+} \\ \text { SS1 } & 87 \pm 4 & >99 & 88 \pm 3 & >99 & >99 & - \\ \text { SS2 } & 66 \pm 4 & >99 & 36 \pm 1 & >99 & >99 & -2 \\ \text { SS3 } & 87 \pm 16 & >99 & 45 \pm 7 & 99 \pm 0 & >99 & -7.3 \\ \text { SS4 } & 95 \pm 2 & >99 & 38 \pm 2 & 99 \pm 0 & >99 & -7.3 \\ \text { SS5 } & 97 \pm 0 & 17 \pm 2 & 85 \pm 2 & 22 \pm 2 & 41 \pm 7 & 10 \pm 4\end{array}$

tion capacities, notably for $4 \mathrm{tOP}(87 \%$ to $55 \%$; Figure $7 \mathrm{~b})$. For the two solutions, the $\mathrm{pH}$ values ranged from 6 to 8 .

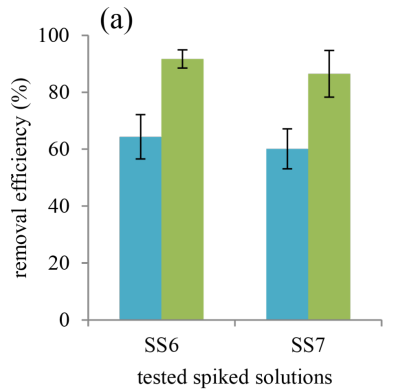

- light PAHs = heavy PAHs (b)

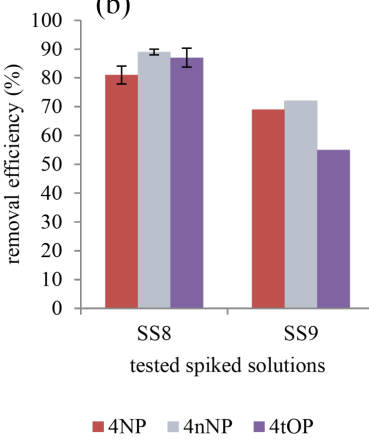

Figure 7: Removal efficiency (\%) after treatment with activated polyBTCA-CD (concentration $=2 \mathrm{~g} \cdot \mathrm{L}^{-1}$ ) for (a) two concentrations of PAHs: low for SS6 and high for SS7 $(n=3)$ and (b) two concentrations of APS: low for SS8 $(n=3)$ and high for SS9 $(n=1)$ (4NP: 4-nonylphenol, 4nNP: 4-n-nonylphenol, 4tOP: 4-tert-octylphenol).

\section{Mixed metal and organic adsorption}

Table 2 presents the adsorption results for the seven mixtures containing metals, PAHs, and APs. Firstly, it was noted that the removal efficiency observed in the solutions containing only one type of substance was similar to those observed in the previous experiments. The heavy PAHs were retained more than the lighter PAHs in each mixture. No adsorption difference was observed between the mixtures containing a single family of substance and those containing two or three families of substances.

\section{Adsorption capacities with discharge waters Metal adsorption in industrial discharge waters}

The polymer was then tested on DWs from a ST company that is specialized in chemical coatings and any processes for the corrosion protection of metal parts intended for the automotive and building sectors. The average concentrations of the main elements present in the industrial DW are reported in Table 3.

In DWs, no $\mathrm{pH}$ variation was observed during the experiment $(\mathrm{pHi}=\mathrm{pHf}=8)$. The results indicate that the retention of the five metals studied above did not reach the removal efficiency obtained in SS, except for $\mathrm{Al}^{3+}$ (70\% on average, Figure 8). Indeed, for $\mathrm{Co}^{2+}, \mathrm{Cr}^{3+}, \mathrm{Ni}^{2+}$ and $\mathrm{Zn}^{2+}$, the removal efficiencies did not exceed $30 \%$. Nevertheless, it appears that other elements in DWs were retained by the polymer $(20 \%, 34 \%, 4 \%$,

\begin{tabular}{|c|c|c|c|c|c|c|c|c|}
\hline & & metals & PAHs & APs & metals + PAHs & metals + APs & $\mathrm{PAHs}+\mathrm{APs}$ & metals + PAHs + APs \\
\hline \multirow{5}{*}{ metals } & $\mathrm{Al}^{3+}$ & $66 \pm 4$ & - & - & $65 \pm 14$ & $63 \pm 5$ & - & $65 \pm 5$ \\
\hline & $\mathrm{Co}^{2+}$ & $>99$ & - & - & $99 \pm 1$ & $99 \pm 1$ & - & $99 \pm 1$ \\
\hline & $\mathrm{Cr}^{3+}$ & $36 \pm 1$ & - & - & $28 \pm 8$ & $25 \pm 13$ & - & $24 \pm 13$ \\
\hline & $\mathrm{Ni}^{2+}$ & $>99$ & - & - & $98 \pm 2$ & $98 \pm 1$ & - & $98 \pm 1$ \\
\hline & $\mathrm{Zn}^{2+}$ & $>99$ & - & - & $96 \pm 4$ & $96 \pm 4$ & - & $96 \pm 4$ \\
\hline \multirow{3}{*}{$\mathrm{PAHs}$} & light & - & $60 \pm 7$ & - & $63 \pm 3$ & - & $62 \pm 8$ & $62 \pm 4$ \\
\hline & heavy & - & $87 \pm 8$ & - & $81 \pm 10$ & - & $87 \pm 3$ & $89 \pm 5$ \\
\hline & $4 \mathrm{NP}$ & - & - & $80 \pm 3$ & - & $82 \pm 7$ & $80 \pm 11$ & $81 \pm 1$ \\
\hline \multirow[t]{2}{*}{ APs } & $4 \mathrm{nNP}$ & - & - & $89 \pm 1$ & - & $90 \pm 2$ & $85 \pm 1$ & $81 \pm 2$ \\
\hline & $4 \mathrm{tOP}$ & - & - & $83 \pm 3$ & - & $86 \pm 6$ & $86 \pm 6$ & $82 \pm 4$ \\
\hline pHf & & 7.3 & 7.6 & 8 & 7.7 & 7.7 & 7.7 & 7.9 \\
\hline
\end{tabular}


Table 3: Average concentrations expressed in $\mathrm{mg} \cdot \mathrm{L}^{-1}$ and standard errors of the main elements present in the DWs $(n=5)$

\begin{tabular}{llllll}
$\mathrm{Al}^{3+}$ & $\mathrm{Co}^{2+}$ & $\mathrm{Cr}^{3+}$ & $\mathrm{Ni}^{2+}$ & $\mathrm{Zn}^{2+}$ & $\mathrm{Ca}^{2+}$ \\
\hline $1.48 \pm 0.54$ & $1.70 \pm 0.74$ & $0.04 \pm 0.03$ & $0.25 \pm 0.11$ & $0.90 \pm 0.50$ & $690 \pm 156$ \\
\hline $\mathrm{Fe}^{3+}$ & $\mathrm{K}^{+}$ & $\mathrm{Mg}^{2+}$ & $\mathrm{Mn}^{2+}$ & $\mathrm{Sr}^{2+}$ & \\
\hline $0.23 \pm 0.12$ & $73.3 \pm 6.56$ & $2.84 \pm 0.31$ & $0.12 \pm 0.1$ & $0.24 \pm 0.03$ &
\end{tabular}

$10 \%, 32 \%$, and $18 \%$ for $\mathrm{Ca}^{2+}, \mathrm{Fe}^{3+}, \mathrm{K}^{+}, \mathrm{Mg}^{2+}, \mathrm{Mn}^{2+}$ and $\mathrm{Sr}^{2+}$, respectively). Taking into account the initial concentrations of these elements (Table 3 ), this means that non-negligible amounts were retained. For instance, $134 \mathrm{mg} \cdot \mathrm{L}^{-1}$ of $\mathrm{Ca}^{2+}$ was retained by the polymer, equivalent to $1.67 \mathrm{mmol} \cdot \mathrm{g}^{-1}$. However, when the initial polymer concentration increased, the removal efficiencies for the metals $\mathrm{Co}^{2+}, \mathrm{Cr}^{3+}, \mathrm{Ni}^{2+}$ and $\mathrm{Zn}^{2+}$ also increased (Table 4). For instance, with a polymer concentration of $10 \mathrm{~g} \cdot \mathrm{L}^{-1}$ (instead of $2 \mathrm{~g} \cdot \mathrm{L}^{-1}$ in Figure 5), retention reached $85 \%, 39 \%, 45 \%$ and $69 \%$ for $\mathrm{Al}^{3+}, \mathrm{Co}^{2+}, \mathrm{Ni}^{2+}$ and $\mathrm{Zn}^{2+}$, respectively. At the same time, the retention of the other inorganic elements also increased $(57 \%, 71 \%, 10 \%, 35 \%, 73 \%$ and $54 \%$ for $\mathrm{Ca}^{2+}, \mathrm{Fe}^{3+}, \mathrm{K}^{+}, \mathrm{Mg}^{2+}, \mathrm{Mn}^{2+}$ and $\mathrm{Sr}^{2+}$, respectively).

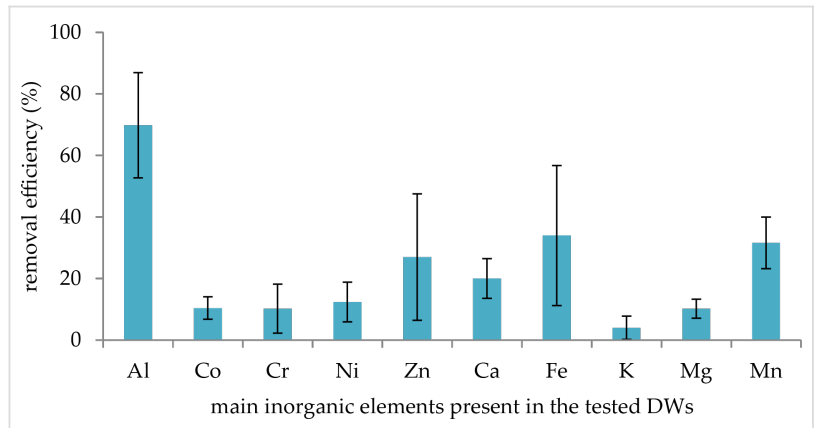

Figure 8: Removal efficiency (\%) of inorganic elements after treatment of five DWs by polyBTCA-CD (concentrations $=2 \mathrm{~g} \cdot \mathrm{L}^{-1}, n=5$ ).

\section{Detailed analysis of the discharge water after treatment with polyBTCA-CD}

Among the 189 substances/parameters analyzed in the raw DW, 35 were detected: sixteen inorganic elements including twelve metals, and seven APs (Table 5). The treatment by activated polyBTCA-CD affected all water parameters and all substances detected in the raw DW except for $\mathrm{Na}$. As in previous experiments on DWs, it was observed that the metals were not efficiently adsorbed by the polymer with a removal efficiency reaching $24 \%, 12 \%, 17 \%$ and $44 \%$ for $\mathrm{Al}^{3+}, \mathrm{Co}^{2+}, \mathrm{Ni}^{2+}$ and $\mathrm{Zn}^{2+}$, respectively. Unlike metals, it appears that most of the organics were retained with removal efficiencies higher than $50 \%$; for example 4tOP, $4 \mathrm{nNP}$, monoethoxylate nonylphenol and monoethoxylate octylphenol were efficiently removed (81, 66,83 and $77 \%$, respectively). Moreover, some substances were retained in large quantities on the polyBTCA-CD such as chloride $\left(130 \mathrm{mg} \cdot \mathrm{L}^{-1}\right)$ and calcium $\left(119 \mathrm{mg} \cdot \mathrm{L}^{-1}\right)$, which is not reflected by the removal efficiency because of the large amounts present in the initial DW. The sodium concentration remained stable after adsorption due to the fact that the material was initially activated by $\mathrm{NaHCO}_{3}$.

\section{Discussion}

To explain the adsorption performance of polyBTCA-CD, a chemisorption mechanism involving several interactions can occur including ion exchange, electrostatic interactions, inclusion complexation and/or precipitation [3,12-16].

Table 4: Removal efficiency of inorganic elements (\%) in DW according to polymer concentration.

removal efficiency (\%)

\begin{tabular}{|c|c|c|c|c|c|c|c|c|c|c|c|c|}
\hline $\begin{array}{l}\text { polymer } \\
\text { concentration }\left(g \cdot L^{-1}\right)\end{array}$ & $\mathrm{Al}^{3+}$ & $\mathrm{Co}^{2+}$ & $\mathrm{Cr}^{3+}$ & $\mathrm{Ni}^{2+}$ & $\mathrm{Zn}^{2+}$ & $\mathrm{Ca}^{2+}$ & $\mathrm{Fe}^{3+}$ & $\mathrm{K}^{+}$ & $\mathrm{Mg}^{2+}$ & $\mathrm{Mn}^{2+}$ & $\mathrm{Sr}^{2+}$ & $\mathrm{pH}$ \\
\hline 5 & 81 & 27 & $>98$ & 37 & 62 & 34 & 63 & 44 & 4 & 0 & 32 & 5 \\
\hline 10 & 85 & 39 & $>98$ & 47 & 69 & 57 & 71 & 42 & 9 & 35 & 56 & 5 \\
\hline 15 & 88 & 46 & $>98$ & 42 & 74 & 74 & 69 & 40 & 13 & 55 & 72 & 5 \\
\hline 20 & 88 & 52 & $>98$ & 47 & 74 & 86 & 70 & 36 & 22 & 72 & 84 & 5 \\
\hline
\end{tabular}




\begin{tabular}{|c|c|c|c|c|}
\hline & & $\begin{array}{l}\text { initial } \\
\text { concentration }\end{array}$ & $\begin{array}{l}\text { final } \\
\text { concentration }\end{array}$ & removal $(\%)$ \\
\hline \multirow{9}{*}{ physicochemical parameters $\left(\mathrm{mg} \cdot \mathrm{L}^{-1}\right)$} & $\mathrm{pH}$ & 8 & 8 & - \\
\hline & BOD-5 & 60 & 56 & 7 \\
\hline & COD & 847 & 325 & 62 \\
\hline & hydrocarbon index $\mathrm{C} 10-\mathrm{C} 40$ & 0.8 & 0.2 & 75 \\
\hline & total cyanide & 0.39 & 0.35 & 10 \\
\hline & AOX & 1.6 & 0.9 & 42 \\
\hline & nitrites & 121 & 105 & 13 \\
\hline & Kjeldahl nitrogen & 44 & 30 & 31 \\
\hline & total nitrogen & 200 & 182 & 9 \\
\hline \multirow{16}{*}{ inorganic elements $\left(\mathrm{mg} \cdot \mathrm{L}^{-1}\right)$} & chloride & 3140 & 3010 & 4 \\
\hline & sulphate & 208 & 201 & 3 \\
\hline & potassium & 98 & 94 & 4 \\
\hline & calcium & 787 & 668 & 15 \\
\hline & magnesium & 2.3 & 2.1 & 9 \\
\hline & manganese & 0.11 & 0.09 & 17 \\
\hline & sodium & 1666 & 1667 & - \\
\hline & sulfur & 91 & 83 & 9 \\
\hline & aluminum & 0.09 & 0.07 & 24 \\
\hline & cobalt & 2.82 & 2.49 & 12 \\
\hline & iron & 0.37 & 0.27 & 27 \\
\hline & molybdenum & 0.07 & 0.06 & 9 \\
\hline & nickel & 0.34 & 0.28 & 17 \\
\hline & selenium & 0.1 & 0.09 & 10 \\
\hline & strontium & 0.27 & 0.26 & 7 \\
\hline & zinc & 0.9 & 0.5 & 44 \\
\hline \multirow{10}{*}{ organic substances $\left(\mu \mathrm{g} \cdot \mathrm{L}^{-1}\right)$} & 1,2-dichloroethane & 1.2 & 0.7 & 42 \\
\hline & chloroform & 4.4 & 3.2 & 27 \\
\hline & dichlorobromomethane & 0.8 & $<0.5$ & $>38$ \\
\hline & 4-tert-octylphenol & 2.1 & 0.4 & 81 \\
\hline & 4-nonylphenol & 0.3 & $<0.1$ & $>66$ \\
\hline & monoethoxylate nonylphenol & 5.62 & 0.97 & 83 \\
\hline & diethoxylate nonylphenol & 2.05 & 0.96 & 53 \\
\hline & monoethoxylate octylphenol & 177 & 41 & 77 \\
\hline & diethoxylate octylphenol & 177 & 130 & 27 \\
\hline & 4-tert-butylphenol & 26 & 14 & 46 \\
\hline
\end{tabular}

The polymer, without an activation step, removed $20 \%$ of the total metal load in spiked solutions (SS) containing five metals at $10 \mathrm{mg} \cdot \mathrm{L}^{-1}$ each. This could be attributed to surface adsorption and diffusion into the polymer network. However, it was observed that an activation step in an aqueous solution of sodium bicarbonate was necessary to enhance metal retention, as also reported by Ducoroy et al. [17], allowing for a removal efficiency for metals higher than $99 \%$ for $\mathrm{Co}^{2+}, \mathrm{Ni}^{2+}$ and $\mathrm{Zn}^{2+}$, through both electrostatic interactions and ion exchange. Indeed, during the process of polymer synthesis, the crosslinking agent BTCA was used, this compound presents four carboxylic functions and a previous study [18] showed that only two of its carboxylic groups reacted with the CD units to form the polymer network, the two remaining ones being available to react with cations through chemisorption (electrostatic interactions and ion exchange). Moreover, this treatment only converted carboxylic groups into carboxylate without altering the amorphous structure of the polymer, as seen from the X-ray spectra.

Precipitation could also explain the removal efficiency enhancement observed with the activated polymer since it induced a strong $\mathrm{pH}$ increase. Indeed, for the solution of five metals at concentration of $1 \mathrm{mg} \cdot \mathrm{L}^{-1}(\mathrm{SS} 2)$ treated with activated 
polyBTCA-CD, the $\mathrm{pH}$ increased from 4.4 to 7.3 , probably due to the basic character of the polymer, the $\mathrm{COOH}$ groups of which have been converted into $\mathrm{COO}^{-} \mathrm{Na}^{+}$groups inducing metal precipitation, notably for $\mathrm{Al}^{3+}$ and $\mathrm{Cr}^{3+}$.

With the highest concentration tested $\left(10 \mathrm{mg} \cdot \mathrm{L}^{-1}\right.$, which corresponds to $5 \mathrm{mg}$ of each metal per gram of polymer), the removal efficiency represents $0.466 \mathrm{mmol}$ of metals adsorbed per gram of polymer, that is lower than the theoretical ion exchange capacity, estimated by titration to be $0.705 \mathrm{mmol}$ of $\mathrm{COOH}$ functional groups per gram of polymer. In theory, in order to saturate the $\mathrm{COOH}$ functional groups, a concentration of $6.5 \mathrm{mg}$ of each metal per gram of polymer (i.e., $13 \mathrm{mg} \cdot \mathrm{L}^{-1}$ ) would have been necessary. In the DWs, focusing on $\mathrm{Ca}^{2+}$ only, $119 \mathrm{mg} \cdot \mathrm{L}^{-1}$ were retained by the polymer, representing a concentration of $1.49 \mathrm{mmol} \cdot \mathrm{g}^{-1}$ of material. Thus, the IEC of the polymer $\left(0.705 \mathrm{mmol} \cdot \mathrm{g}^{-1}\right)$ was exceeded. This observation confirmed the fact that the inorganic elements were not only retained by ion exchange and/or electrostatic interactions, but other interactions occurred, such as precipitation and/or physical phenomena (surface adsorption, diffusion into the network and/or hydrogen bonding).

This study demonstrated the efficiency of activated polyBTCA$\mathrm{CD}$ to treat the inorganic load, but also to treat the organic pollutants. It can be noted that the analysis of 26 substances present in the DW tested, showed that the polymer is able to adsorb 4-tert-butylphenol, 1,2-dichloroethane and chloroform, but also APs and the organo-halogenated compounds (represented by the AOX parameter). For the retention of APs, no difference was noted between 4NP, 4nNP and 4tOP. Heavy PAHs were better retained than light ones. This observation could be partially explained by the greater hydrophobicity of heavy PAHs compared with light ones [19]. Indeed, in the case of interactions with organics, CD units play an important role. The hydrophobic cavities of these molecules allow for the formation of inclusion complexes with $\mathrm{PAH}$ guest molecules (organic substances) $[3,20]$. If the guest compounds present an appropriate molecular size and structure to enter into the CD cavity the more hydrophobic the organic substances, the more stable the inclusion complexes.

The material was also able to efficiently treat complex solutions containing metals, PAHs, APs and other substances. However, although in spiked solutions no competition effect was revealed between substance groups, these phenomena appeared in more complex solution such as DWs. Indeed, the retention of inorganic elements decreased from an average of $87 \%$ for the five metals in SS to $26 \%$ in DWs. It appears that other elements present in DW were retained by the polymer, for instance $\mathrm{Fe}^{3+}$, $\mathrm{Mn}^{2+}, \mathrm{Mg}^{2+}$ and $\mathrm{Ca}^{2+}$. Discharge waters from ST industries are complex matrices containing not only metals, PAHs or APs but also other elements including anions and salts, sometimes exceeding one gram per liter [21]. In this study, calcium and chlorides were present in the DWs at concentrations of 500 and $3000 \mathrm{mg} \cdot \mathrm{L}^{-1}$, respectively. In fact, a large amount of these other inorganic elements could interact with the polymer, notably $\mathrm{Ca}^{2+}$, which was retained at $119 \mathrm{mg} \cdot \mathrm{L}^{-1}$. Thus, the low retention of target metals $\left(\mathrm{Al}^{3+}, \mathrm{Co}^{2+}, \mathrm{Cr}^{3+}, \mathrm{Ni}^{2+}\right.$ and $\left.\mathrm{Zn}^{2+}\right)$ by the adsorbent could be due to the simultaneous presence of high quantities of $\mathrm{K}^{+}, \mathrm{Na}^{+}, \mathrm{Mg}^{2+}$ or $\mathrm{Ca}^{2+}$, which can saturate the carboxylate functions of the polymer and compete with the target metals for access to the active sites [22-25]. These observations were confirmed by the tests conducted in SS in the presence of calcium. An increase of polymer concentration in DWs $\left(10 \mathrm{~g} \cdot \mathrm{L}^{-1}\right.$ instead of $\left.2 \mathrm{~g} \cdot \mathrm{L}^{-1}\right)$ yielded better results in terms of removal efficiency for all metals. However, while the retention of $\mathrm{Co}^{2+}, \mathrm{Ni}^{2+}$ and $\mathrm{Zn}^{2+}$ was reduced in the presence of $\mathrm{Ca}^{2+}$, this was not always the case for $\mathrm{Al}^{3+}$ and $\mathrm{Cr}^{3+}$. In some cases, $\mathrm{Al}^{3+}$ and $\mathrm{Cr}^{3+}$ exhibited unexpected behavior.

In solutions at low concentrations ( $\mathrm{SS} 2, \mathrm{SS} 3$ and $\mathrm{SS} 4), \mathrm{Al}^{3+}$ and $\mathrm{Cr}^{3+}$ were removed with low efficiency compared to other metals, but in solutions at higher concentrations (SS1) or in the presence of calcium (SS5), an increase of removal efficiency was observed whereas for the three other metals, retention decreased. In the case of mixtures, the same observations were made, $\mathrm{Al}^{3+}$ and $\mathrm{Cr}^{3+}$ removal being systematically lower, whereas for the three other metals the removal efficiency remained as high as $99 \%$. Moreover, in DWs, $\mathrm{Al}^{3+}$ was retained by an average of $60 \%$ while the others did not exceed a removal efficiency of $30 \%$. No simple explanation could clarify these phenomena but some specific characteristics of these two metals must be pointed out. Indeed, the behavior of both $\mathrm{Al}^{3+}$ and $\mathrm{Cr}^{3+}$ is highly $\mathrm{pH}$ dependent, with complex speciation patterns [26-28]. Since the $\mathrm{pH}$ value was not kept constant during tests, the $\mathrm{pH}$ variations probably led to changes in speciation of the two metals, leading to this unexpected behavior compared to the other metals. Moreover, it can be noted that $\mathrm{Al}^{3+}$ and $\mathrm{Cr}^{3+}$ have the smallest ionic radii of the five metals and a low electronegativity, which are two parameters that decrease metal removal as described by Al-Rub and co-workers [29].

\section{Conclusion}

Throughout this study, it was demonstrated that polyBTCA-CD is a versatile sorbent able to retain substances present at concentrations close to a few milligrams per liter (metals and other inorganic elements) but also at trace concentrations $\left(\mu \mathrm{g} \cdot \mathrm{L}^{-1}\right.$ for organics). Although ion exchange on the one hand, and host-guest inclusion on the other hand were the main phenomena interacting between adsorbent and solutes, the interpretation 
of the results was made difficult due to the wide diversity of polluting species present in DWs, involving numerous other mechanisms in the adsorption (classified for instance as chemisorption and physisorption phenomena) $[3,12,20]$. Thus, further studies are needed to better understand how water parameters impact the different routes of pollutant retention, which is of great interest for future applications of non-conventional adsorbents in industry.

\section{Experimental Synthesis and characterization of the material}

The cross-linked polymer (Figure 1) was prepared in a single step by crosslinking hydroxypropyl- $\beta$-cyclodextrin (HP $\beta C D$; Kleptose HPB ${ }^{\circledR}$, DS $=0.62$, Roquette, Lestrem, France) using 1,2,3,4-butanetetracarboxylic acid (BTCA; Aldrich, Milwaukee, WI). The synthesis procedure has already been described in detail by Martel et al. [10,30]. Based from their methodology, the typical cross-linking reaction was carried out as follows: in a reactor, $0.37 \mathrm{~mol} \cdot \mathrm{L}^{-1}$ of sodium dihydrogenophosphate $\left(\mathrm{Na}_{2} \mathrm{H}_{2} \mathrm{PO}_{2} \cdot \mathrm{H}_{2} \mathrm{O}\right.$, catalyst $), 0.85 \mathrm{~mol} \cdot \mathrm{L}^{-1}$ of BTCA and $0.18 \mathrm{~mol} \cdot \mathrm{L}^{-1}$ of $\mathrm{HP} \beta \mathrm{CD}$ were dissolved; the resulting solution was then concentrated by evaporation, and the mixture heated to $140^{\circ} \mathrm{C}$. These last two steps were performed under vacuum in a rotary evaporator; the polymer formed was re-suspended through addition of water to the reactor; the polymer was then filtered and purified by several washings with water. It was dried at $50{ }^{\circ} \mathrm{C}$ until constant weight, yielding a white powder. The yield of the reaction was equal to $87.6 \%$.

To activate the polyBTCA-CD by converting the carboxylic functions to their carboxylate form, the material was stirred for $4 \mathrm{~h}$ in an aqueous solution of $4 \mathrm{~g} \cdot \mathrm{L}^{-1} \mathrm{NaHCO}_{3}$ (saturated) then extensively washed with osmosed water to remove unreacted reagents, and finally oven dried at $50{ }^{\circ} \mathrm{C}$.

The ion exchange capacity (IEC) of the material was determined by $\mathrm{pH}$-metric titration according to the calcium acetate method [31]. A solution of calcium acetate $(2 \% \mathrm{w} / \mathrm{w})$ was prepared in osmosed water. A weighed sample of dry polymer was stirred into the calcium acetate solution for $2 \mathrm{~h}$ following calibration with oxalic acid. Then, the solution was filtered, and the amount of acetic acid formed was measured by titration using a sodium hydroxide solution $(0.05 \mathrm{M})$. The amount of ion exchange functions was equal to the amount of acetic acid present in solution. The results were expressed in mmol of $\mathrm{COOH}$ functional groups per gram of polymer.

The point of zero charge (PZC) values of both non-activated and activated polyBTCA-CD were determined by titration with the salt addition method. $50 \mathrm{~mL}$ of $0.1 \mathrm{M} \mathrm{NaCl}$ solution was placed in each of nine beakers. The $\mathrm{pH}$ of each solution was adjusted from 3 to 11 with one $\mathrm{pH}$ unit increment using a $\mathrm{pH}$ meter ( $\mathrm{pH}$ meter, model 3110, WTW, Alès, France) with aqueous $0.1 \mathrm{M} \mathrm{NaOH}$ and $0.1 \mathrm{M} \mathrm{HCl}$. Then $0.15 \mathrm{~g}$ of polymer was added to each beaker. The solutions were stirred for $48 \mathrm{~h}$ to reach equilibrium then the resulting $\mathrm{pH}$ ( $\mathrm{pHf}$ ) was measured. The difference between the initial and final $\mathrm{pH}$ values $(\Delta \mathrm{pH})$ was plotted against the initial $\mathrm{pH}$. The PZC was represented by the point $\Delta \mathrm{pH}=0$ [32].

X-ray diffraction analysis (XRD) was performed on a Bruker D8 Advance diffractometer using $\mathrm{Cu} \mathrm{K} \alpha$ radiation with a wavelength of $\lambda=0.15406 \mathrm{~nm}$ produced at $40 \mathrm{kV}$ and $40 \mathrm{~mA}$. XRD data were collected over the $2 \theta$ range from $10^{\circ}$ to $60^{\circ}$ at every $0.02^{\circ}$ with a scan speed of $0.5 \mathrm{~s}$ per step. For polymer, the diffraction profiles are divided into 2 parts: peaks related to diffraction of crystallites and a broad peak related to scattering of the amorphous phase. The assumption is that the areas are proportional to the scattering intensities of crystalline and amorphous phases. Thus, the percentage of polymer that is crystalline was determined from Equation 1 [33]:

$$
\% \text { crystallinity }=\frac{\text { area under crystalline peaks }}{\text { total area under all peaks }} \times 100 \text {. }
$$

The polymer was also characterized by solid-state ${ }^{13} \mathrm{C}$ NMR techniques such as cross polarization magic angle spinning (CP MAS) and MAS. The spectra were recorded with a Bruker spectrometer operating at $75.47 \mathrm{MHz}$ and $303 \mathrm{~K}$. The compounds were placed in a zirconium rotor, $4 \mathrm{~mm}$ in diameter and $21 \mathrm{~mm}$ high. The chemical shifts were recorded relative to tetramethylsilane with benzene as secondary reference. The Hartmann-Hahn condition was satisfied during cross polarization magic angle with $1.5 \mathrm{~ms}$ of contact time under the following conditions: repetition time $8 \mathrm{~s}, 1 \mathrm{H} 90^{\circ}$ pulse length $4 \mu \mathrm{s}$, and spin rate at $10 \mathrm{kHz}$.

\section{Adsorption tests}

To determine the ability of the material to treat inorganic and organic load, several batch experiments were carried out with two kinds of solutions: spiked solutions (SS) containing different substances at several concentrations that are typical of ST discharge waters (DWs) [34] and real ST industrial DWs themselves.

SS contained metal sulfate salts $\left(\mathrm{Al}_{2}\left(\mathrm{SO}_{4}\right)_{3} \cdot 16 \mathrm{H}_{2} \mathrm{O}\right.$; $\left.\mathrm{CoSO}_{4} \cdot 7 \mathrm{H}_{2} \mathrm{O} ; \mathrm{CrK}\left(\mathrm{SO}_{4}\right)_{2} \cdot 12 \mathrm{H}_{2} \mathrm{O} ; \mathrm{NiSO}_{4} \cdot 6 \mathrm{H}_{2} \mathrm{O} ; \mathrm{ZnSO}_{4} \cdot 7 \mathrm{H}_{2} \mathrm{O}\right)$ purchased from Aldrich and used without further purification. The sixteen PAHs of the US EPA list [35] and three APs were purchased from Supelco Sigma Aldrich (Saint-Quentin Fallavier, France) and used as received; eight light PAHs: naph- 
thalene (NAP), acenaphthene (ACE), acenaphthylene (ACY), fluorene (FLU), phenanthrene (PHE), anthracene (ANT), fluoranthene (FLT) and pyrene (PYR); eight heavy PAHs: benz $[a]$ anthracene (BaANT), chrysene (CHY), benzo[ $b]$ fluoranthene (BbFLT), benzo[k]fluoranthene (BkFLT), benzo $[a]$ pyrene (BaPYR), dibenz $[a, h]$ anthracene (dBahANT), indeno[1,2,3-cd]pyrene (IcdPYR) and benzo $[g, h, i]$ perylene (BghiPL); three APs: 4-nonylphenol (4NP, CAS no. 84852-15-3), 4-n-nonylphenol (4nNP, CAS no. 104-40-5) and 4-tert-octylphenol (4tOP, CAS no. 140-66-9). Calcium chloride and sodium bicarbonate were purchased from Fischer Scientific (Illkirch, France) and used as received. Each SS was prepared from stock solutions in osmosed water.

\section{Metal adsorption}

In order to examine the effect of $\mathrm{NaHCO}_{3}$ treatment (activation), the adsorption capacities of the non-activated and the activated polymer polyBTCA-CD were compared with a solution containing the five metals $\left(\mathrm{Al}^{3+}, \mathrm{Co}^{2+}, \mathrm{Cr}^{3+}, \mathrm{Ni}^{2+}\right.$ and $\mathrm{Zn}^{2+}$ ) each at a concentration of $10 \mathrm{mg} \cdot \mathrm{L}^{-1}$. A kinetic study was also performed to determine the appropriate contact time between the material and the polymetallic solutions at concentrations of 1 and $10 \mathrm{mg} \cdot \mathrm{L}^{-1}$ for each metal. Then, metal adsorption was determined by several polymetallic solutions containing the five metals described previously. Different concentrations of metals were tested: $10 \mathrm{mg} \cdot \mathrm{L}^{-1}(\mathrm{SS} 1)$ and $1 \mathrm{mg} \cdot \mathrm{L}^{-1}$ (SS2) for each metal and two solutions reproducing DW concentrations (SS3 and SS4). Moreover, two experiments were performed with metals in the absence (SS4) or presence (SS5) of $\mathrm{CaCl}_{2}$ at DW concentrations, in order to observe the influence of salt concentrations (Table 6).

Table 6: Concentrations of metals and calcium expressed in $\mathrm{mg} \cdot \mathrm{L}^{-1}$ in the spiked solutions.

\begin{tabular}{llllllll} 
& $\mathrm{Al}^{3+}$ & $\mathrm{Co}^{2+}$ & $\mathrm{Cr}^{3+}$ & $\mathrm{Ni}^{2+}$ & $\mathrm{Zn}^{2+}$ & $\mathrm{Ca}^{2+}$ & $\mathrm{pHi}$ \\
\hline SS1 & 9.12 & 9.71 & 10.05 & 9.46 & 9.37 & $<0.5$ & 3.9 \\
SS2 & 0.91 & 0.97 & 1.01 & 0.95 & 0.94 & $<0.5$ & 4.4 \\
SS3 & 0.95 & 0.76 & 0.015 & 0.10 & 0.36 & $<0.5$ & 4.8 \\
SS4 & 2.17 & 1.34 & 0.038 & 0.20 & 0.76 & $<0.5$ & 4.8 \\
SS5 & 2.26 & 1.33 & 0.035 & 0.20 & 0.75 & 457 & 4.7
\end{tabular}

\section{PAH and AP adsorption}

To determine the PAH adsorption, solutions were prepared with the sixteen PAHs: eight were considered as light PAHs, i.e., with a lower molecular weight, (NAP, ACY, ACE, FLU, PHE, ANT, FLT, PYR) and eight as heavy PAHs (BaANT, CHY, BbFLT, BkFLT, BaPYR, IcdPYR, dBahANT, BghiPL). Two PAH concentrations were tested: 3229 and $7243 \mathrm{ng} \cdot \mathrm{L}^{-1}$ for the sum of the sixteen PAHs, i.e., for the first an average concentra- tion of $1543 \pm 261 \mathrm{ng} \cdot \mathrm{L}^{-1}$ and $1686 \pm 410 \mathrm{ng} \cdot \mathrm{L}^{-1}$ (SS6; pHi 6), and for the second an average of $3508 \pm 454 \mathrm{ng} \cdot \mathrm{L}^{-1}$ and $3735 \pm 333 \mathrm{ng} \cdot \mathrm{L}^{-1}(\mathrm{SS} 7$; pHi 6$)$ for the sum of the light and the heavy PAHs, respectively. In the case of the APs, 4NP, 4nNP and $4 \mathrm{tOP}$ were used to prepare solutions at two concentrations: SS8 (pHi 6) containing 44, 53 and $59 \mu \mathrm{g} \cdot \mathrm{L}^{-1}$ and SS9 (pHi 6) containing 662, 720 and $889 \mu \mathrm{g} \cdot \mathrm{L}^{-1} 4 \mathrm{NP}, 4 \mathrm{nNP}$ and $4 \mathrm{tOP}$, respectively.

\section{Metals and organic adsorption in mixtures}

To study adsorption capacities when substances are in mixture, seven solutions were prepared: mixture of five metals ( $\mathrm{pHi} 4.4$ ), mixture of sixteen PAHs (pHi 6), mixture of three APs (pHi 6), mixture of five metals +16 PAHs (pHi 4.4), mixture of five metals + three APs (pHi 4.4), mixture of 16 PAHs + three APs (pHi 6.1) and mixture of five metals + 16 PAHs + three APs (pHi 4.4). In each solution, the average concentration was $1.08 \pm 0.11 \mathrm{mg} \cdot \mathrm{L}^{-1}$ for each metal, $365 \pm 29 \mathrm{ng} \cdot \mathrm{L}^{-1}$ for each light $\mathrm{PAH}, 419 \pm 24 \mathrm{ng} \cdot \mathrm{L}^{-1}$ for each heavy $\mathrm{PAH}$ and $53 \pm 24 \mu \mathrm{g} \cdot \mathrm{L}^{-1}$ for each AP.

\section{Adsorption capacities in discharge waters}

Five samples of real discharge waters (DWs) were collected from Zindel Industry located in Seloncourt (Doubs, France) which is specialized in chemical coatings and any processes for the corrosion protection of metal parts intended for the automotive and building sectors. Their process waters mainly contain metallic pollutants (e.g., $\mathrm{Cr}^{3+}, \mathrm{Ni}^{2+}$ and $\mathrm{Zn}^{2+}$ ) coming from rinsing and washing baths. Following the tests conducted on SS, metal retention capacity was also tested on five different industrial DWs. In one DW, the effect of polymer dose was tested: 5 , 10,15 and $20 \mathrm{~g} \cdot \mathrm{L}^{-1}$. Moreover, one more detailed analysis was performed in order to see if the polymer can retain other substances present in the DW.

\section{Batch experiments}

In each experiment, $2 \mathrm{~g} \cdot \mathrm{L}^{-1}$ of material was stirred $(250 \mathrm{rpm})$ with a fixed volume of polluted solution (with no modification of the initial $\mathrm{pH}$ value) at room temperature for $4 \mathrm{~h}$. After treatment, the solutions were left to settle for $1 \mathrm{~h}$, and the supernatant was analyzed. Chemical analyses were performed in the initial and in the treated solutions and the results expressed in concentration and removal efficiency. Under the same conditions, a control experiment was performed without pollutants in order to check whether $\mathrm{pH}$ variations occurred in non-activated and activated polyBTCA-CD.

\section{Chemical analyses}

For each SS or DW, initial and final $\mathrm{pH}$ values were measured. Metal concentrations were determined by inductively coupled plasma atomic emission spectroscopy (ThermoFisher, iCAP 
6500 radial model, Courtaboeuf, France) after a step of acid digestion for DWs, following a previously reported method [21]. The analysis of the sixteen PAHs was performed by liquid-liquid extraction with hexane followed by separation and detection on a system composed of a GC apparatus and a triple quadrupole spectrometer (GC-MS/MS, Agilent, Massy, France) according to a method described in detail by Crini and co-workers [36]. Three APs (4NP, 4nNP, 4tOP) were analyzed by a certified laboratory (CARSO LSEHL, Lyon, France), by liquid-liquid extraction followed by separation and detection on GC-MS/MS according to the standard NF EN ISO 18857-1. For the detailed analysis, 189 substances and 17 water parameters were analyzed, before and after treatment of the DW, by a certified laboratory (CARSO LSEHL, Lyon, France).

\section{Acknowledgements}

The authors thank the Agence de l'Eau Rhône Méditerranée Corse, the FEDER (Fonds Européens de Développement Régional) and the Conseil Régional de Franche-Comté for financial support (NIRHOFEX Program 2013-2016) and Peter Winterton (University of Toulouse III, Toulouse, France) for English grammar and syntax review and his critical reading.

\section{References}

1. Morin-Crini, N.; Crini, G. Prog. Polym. Sci. 2013, 38, 344-368. doi:10.1016/j.progpolymsci.2012.06.005

2. Charles, J.; Bradu, C.; Morin-Crini, N.; Sancey, B.; Winterton, P.; Giangiacomo, T.; Badot, P.-M.; Crini, G. J. Saudi Chem. Soc. 2016, 20, 185-194. doi:10.1016/j.jscs.2013.03.007

3. Zhao, F.; Repo, E.; Yin, D.; Meng, Y.; Jafari, S.; Sillanpää, M. Environ. Sci. Technol. 2015, 49, 10570-10580. doi:10.1021/acs.est.5b02227

4. Zhang, X.; Wang, Y.; Yang, S. Carbohydr. Polym. 2014, 114, 521-529. doi:10.1016/j.carbpol.2014.08.072

5. Yang, W.; Yu, Z.; Pan, B.; Lv, L.; Zhang, W. Chem. Eng. J. 2015, 268, 399-407. doi:10.1016/j.cej.2015.01.051

6. Crini, G. Chem. Rev. 2014, 114, 10940-10975. doi:10.1021/cr500081p

7. Kayaci, F.; Aytac, Z.; Uyar, T. J. Hazard. Mater. 2013, 261, 286-294. doi:10.1016/j.jhazmat.2013.07.041

8. Szejtli, J. Carbohydr. Polym. 1990, 12, 375-392. doi:10.1016/0144-8617(90)90088-A

9. Mamba, B. B.; Krause, R. W.; Malefetse, T. J.; Nxumalo, E. N. Environ. Chem. Lett. 2007, 5, 79-84. doi:10.1007/s10311-006-0082-x

10. Martel, B.; Weltrowski, M.; Morcellet, J. Cyclodextrin polymers and/or cyclodextrin derivatives with complexing properties and ion-exchange properties and method for the production thereof. EP1165621B1, Feb $2,2002$.

11. Trotta, F.; Tumiatti, W. Cross-linked polymers based on cyclodextrins for removing polluting agents.. EP1492822A1, Jan 5, 2005.

12. Crini, G. Prog. Polym. Sci. 2005, 30, 38-70. doi:10.1016/j.progpolymsci.2004.11.002

13. Genç-Fuhrman, H.; Mikkelsen, P. S.; Ledin, A. Water Res. 2007, 41, 591-602. doi:10.1016/j.watres.2006.10.024

14. Tao, Z.; Chu, T.; Li, W.; Du, J.; Dai, X.; Gu, Y. Colloids Surf., A 2004, 242, 39-45. doi:10.1016/j.colsurfa.2004.04.044
15. Malamis, S.; Katsou, E. J. Hazard. Mater. 2013, 252-253, 428-461. doi:10.1016/j.jhazmat.2013.03.024

16. Saad, D. M.; Cukrowska, E. M.; Tutu, H. Toxicol. Environ. Chem. 2011, 93, 914-924. doi:10.1080/02772248.2011.575785

17. Ducoroy, L.; Bacquet, M.; Martel, B.; Morcellet, M. React. Funct. Polym. 2008, 68, 594-600. doi:10.1016/j.reactfunctpolym.2007.10.033

18. Ducoroy, L.; Martel, B.; Bacquet, M.; Morcellet, M. J. Appl. Polym. Sci. 2007, 103, 3730-3738. doi:10.1002/app.25249

19. Rollin, C.; Quiot, F. Hydrocarbures aromatiques polycycliques - guide méthodologique - acquisition des données d'entrée des modèles analytiques ou numériques de transferts dans les sols et les eaux souterraines (in French); Ministère de l'Ecologie et du Développement Durable, 2005; Vol. Report $n^{\circ}$ 66244-DESP-R01.

20. Steed, J. W.; Atwood, J. L. Supramolecular chemistry, 2nd ed.; John \& Wiley: United Kingdom, 2009. doi:10.1002/9780470740880

21. Morin-Crini, N.; Druart, C.; Gavoille, S.; Lagarrigue, C.; Crini, G. J. Environ. Prot. 2013, 4, 53-60. doi:10.4236/jep.2013.47A007

22. Brusseau, M. L.; Wang, X.; Wang, W.-Z. Environ. Sci. Technol. 1997, 31, 1087-1092. doi:10.1021/es960612c

23. Reddad, Z.; Gerente, C.; Andres, Y.; Le Cloirec, P. Environ. Sci. Technol. 2002, 36, 2067-2073. doi:10.1021/es0102989

24. Schiewer, S.; Volesky, B. Environ. Sci. Technol. 1997, 31, 2478-2485. doi:10.1021/es960751u

25. Yang, S.; Li, J.; Lu, Y.; Chen, Y.; Wang, X. Appl. Radiat. Isot. 2009, 67, 1600-1608. doi:10.1016/j.apradiso.2009.03.118

26. Chen, T.; Zhou, Z.; Xu, S.; Wang, H.; Lu, W. Bioresour. Technol. 2015, 190, 388-394. doi:10.1016/j.biortech.2015.04.115

27. Gensemer, R. W.; Playle, R. C. Crit. Rev. Environ. Sci. Technol. 1999, 29, 315-450. doi:10.1080/10643389991259245

28. Kratochvil, D.; Pimentel, P.; Volesky, B. Environ. Sci. Technol. 1998, 32, 2693-2698. doi:10.1021/es971073u

29. Al-Rub, F. A. A.; El-Naas, M. H.; Ashour, I.; Al-Marzouqi, M. Process Biochem. 2006, 41, 457-464. doi:10.1016/j.procbio.2005.07.018

30. Martel, B.; Ruffin, D.; Weltrowski, M.; Lekchiri, Y.; Morcellet, M. J. Appl. Polym. Sci. 2005, 97, 433-442. doi:10.1002/app.21391

31. Ducoroy, L.; Martel, B.; Bacquet, B.; Morcellet, M. J. Inclusion Phenom. Macrocyclic Chem. 2007, 57, 271-277. doi:10.1007/s10847-006-9172-4

32. Tan, W.-f.; Lu, S.-j.; Liu, F.; Feng, X.-h.; He, J.-z.; Koopal, L. K. Soil Sci. 2008, 173, 277-286. doi:10.1097/SS.0b013e31816d1f12

33. Alexander, L. J. Mater. Sci. 1971, 6, 93. doi:10.1007/BF00550300

34. Druart, C.; Morin-Crini, N.; Euvrard, E.; Crini, G. Environ. Processes 2016, 3, 59-72. doi:10.1007/s40710-016-0125-7

35. Callahan, M. A.; Slimak, M. W.; Gabel, N. W.; May, I. P.; Fowler, C. F.; Freed, J. R.; Jennings, P.; Durfee, R. L.; Whitmore, F. C.; Maestri, B.; Mabey, W. R.; Holt, B. R.; Gould, C. Water-related environmental fate of 129 priority pollutants, EPA-440/4-79-029a; U. S. Environmental Protection Agency, Office of Water Planning and Standards and Office of Water and Waste Management, 1979.

36. Crini, N.; Druart, C.; Amiot, C.; Gavoille, S.; Crini, G. Environ. Eng. Manage. J. 2015, 14, 1195-1202. 


\section{License and Terms}

This is an Open Access article under the terms of the Creative Commons Attribution License

(http://creativecommons.org/licenses/by/2.0), which permits unrestricted use, distribution, and reproduction in any medium, provided the original work is properly cited.

The license is subject to the Beilstein Journal of Organic Chemistry terms and conditions:

(http://www.beilstein-journals.org/bjoc)

The definitive version of this article is the electronic one which can be found at:

doi:10.3762/bjoc. 12.172 